\title{
Peculiarities of the interface between high-permittivity dielectrics and semiconductors
}

\author{
Nenad Novkovski ${ }^{1,2}$ * \\ 1 Institute of Physics, Faculty of Natural Sciences and Mathematics, Ss Cyril and Methodius University, Skopje, Macedonia \\ 2 Research Center for Environment and Materials, Macedonian Academy of Sciences and Arts, Skopje, Macedonia
}

\section{Edited by:}

Felip Sandiumenge, Consejo Superior de Investigaciones Científicas, Spain

Reviewed by:

Alexey A. Sokol, University College London, UK

Robert Pawel Mroczynski, Warsaw University of Technology, Poland

*Correspondence:

Nenad Novkovski, Institute of

Physics, Faculty of Natural Sciences and Mathematics, Ss Cyril and

Methodius University, Arhimedova 3,

Skopje 1000, Macedonia

e-mail: nenad@iunona.pmt.

ukim.edu.mk
Replacement of the silicon dioxide thin films in metal-oxide-semiconductor structures for microelectronics with high-permittivity dielectrics (high-k) is a crucial step in the further down-scaling of microelectronic devices. Technological development of the fabrication processes and better theoretical understanding of the physical phenomena in the considered structures are demanded simultaneously. Important issues concerning high- $k$ are discussed in this paper and directions for further development are indicated. Further progress also requires better understanding of the physical phenomena appearing in stacked high-k/interfacial layer dielectrics.

Keywords: high- $k$ dielectrics, metal-oxide-semiconductor structures, tunneling, band offsets, permittivity

\section{SILICON DIOXIDE THIN FILMS}

Interfaces in electron devices are part of their basic structure. Functioning of such devices is inseparably connected to the presence of different interfaces. Of particular importance are metal-oxidesemiconductor (MOS) structures, where two conductive materials (metal and semiconductor) are separated by a thin dielectric layer.

Over decades, silicon dioxide has been used as a unique solution for insulating material of MOS structures due to its outstanding properties, such as exceptionally low-defect density and high band offsets both for electrons and holes.

A particular advantage of this material is the possibility to grow silicon dioxide films by oxidation of the silicon substrate itself, thus, avoiding complicated deposition processes. Simultaneously, this fabrication method ensures excellent match of the dielectric layer with the substrate, ensuring low density of defects at the insulator/semiconductor contact.

Nevertheless, there is a thin region near the semiconductor substrate containing several types of imperfections. Densities of these defects are substantially lower then in structures containing other dielectric materials. The region close to the substrate possessing different properties different from those of the bulk is referred to as interfacial layer. The notion of the interfacial layer has undergone substantial alteration since its initial introduction. In the early stage, the interfacial layer was considered a region in the oxide about $10 \mathrm{~nm}$ thick, in which mechanical strains (interface constraints) between the two materials are present (Jaccodine and Schlegel, 1966; Boyd and Wilson, 1987). Substantial deviations from the $\mathrm{SiO}_{2}$ stoichiometry are present in a region about $1 \mathrm{~nm}$ thick (Nakazawa et al., 1989). Using scanning tunneling microscopy and spectroscopy, an interfacial transitional region about $0.9 \mathrm{~nm}$ thick has been found, in which the silicon oxide surface band gap increases gradually with thickness (Xue et al., 2007).
Variations of the bandgap in the substrate are limited to about $0.3 \mathrm{~nm}$. Ab initio studies show that both the optical and the static dielectric constants change abruptly in the vicinity of the $\mathrm{SiO}_{2} / \mathrm{Si}$ interface, while the energy gap changes gradually on the $\mathrm{SiO}_{2}$ side (Wakui et al., 2007). Therefore, the presence of a layer about $1 \mathrm{~nm}$ thick (about three monoatomic layers), having properties different that the bulk $\mathrm{SiO}_{2}$ is to be taken into consideration when studying MOS structures. Such a thin layer also plays a crucial role in the modification of the properties of $\mathrm{SiO}_{2} / \mathrm{Si}$ interface with nitridation (Mi et al., 1993; Novkovski, 1999), which is found to be an important method for improvement of electrical and reliability properties of metal/ $\mathrm{SiO}_{2} / \mathrm{Si}$ structures (Dutoit et al., 1994).

\section{HIGH- $k$ DIELECTRICS}

Progressive down-scaling of the microelectronic devices leads to ultimate decrease of the thickness of the dielectric in MOS structures. Even if introducing the improvements with various technological procedures such as the nitridation, the use of silicon dioxide as dielectric is limited (Novkovski and Atanassova, 2006). Dielectrics with high-relative permittivity (high- $k)\left(\mathrm{Al}_{2} \mathrm{O}_{3}, \mathrm{Ta}_{2} \mathrm{O}_{5}\right.$, $\mathrm{SrTiO}_{3}, \mathrm{TiO}_{2}, \mathrm{ZrO}_{2}, \mathrm{HfO}_{2}, \mathrm{La}_{2} \mathrm{O}_{3}, \mathrm{Lu}_{2} \mathrm{O}_{3}, \mathrm{Sc}_{2} \mathrm{O}_{3}, \mathrm{Dy}_{2} \mathrm{O}_{3}, \mathrm{Y}_{2} \mathrm{O}_{3}$, etc.) and their pseudobinary alloys are studied as a replacement of the silicon dioxide for various microelectronics applications (Wilk et al., 2001; Houssa et al., 2006; Wong and Iwai, 2006; Kittl et al., 2009). The main advantage of high- $k$ dielectrics compared to silicon dioxide is the possibility to obtain the same capacitance with a larger physical thickness $(d)$ of the dielectric layer and thus to reduce the leakage due to direct tunneling occurring in ultrathin $\mathrm{SiO}_{2}$ (thinner than $2 \mathrm{~nm}$ ). Nevertheless, high- $k$ dielectrics have lower heights of tunneling barriers (band offsets, $\Phi$ ), which leads to a somewhat lower benefit from the replacement of the $\mathrm{SiO}_{2}$ with high- $k$. A real measure of the gain in reducing leakage due to 
direct tunneling is roughly given by the ratio of product $\Phi \cdot d$ for the considered materials. For example, band offset for electrons at the $\mathrm{W} / \mathrm{SiO}_{2}$ interface is $\Phi_{\mathrm{e}}=3.45 \mathrm{eV}$, while at the $\mathrm{W} / \mathrm{Ta}_{2} \mathrm{O}_{5}$ interface it is $\Phi_{\mathrm{e}}=0.55 \mathrm{eV}$ (Novkovski, 2006). Relative permittivity for $\mathrm{SiO}_{2}$ is 3.9 while for $\mathrm{Ta}_{2} \mathrm{O}_{5}$ it is about 40 (Kittl et al., 2009), and hence the same capacitance with $\mathrm{Ta}_{2} \mathrm{O}_{5}$ as dielectric will be obtained with 10 times bigger physical thickness of the high- $k$ dielectric than with $\mathrm{SiO}_{2}$. Although the benefit is diminished with the decrease of band offset (by a factor of six), it is still rather important; the capacitance can be doubled at the same level of leakage current.

The above approach is straightforwardly applicable in the case of metal-insulator-metal (MIM) structures. In the case of high- $k$ deposited on semiconductor, during the formation of the high- $k$ layer, however, an interfacial $\mathrm{SiO}_{2}$-containing layer is inevitably formed at the Si substrate (Alers et al., 1998). This interfacial layer substantially modifies properties of MOS structures and hence it deserves particular attention.

\section{ROLE OF THE INTERFACIAL LAYER}

Several authors consider the interfacial layer as unwanted, and they propose different solutions for its reduction or elimination (Engstrom et al., 2012). Indeed, due to the lower permittivity of the interfacial layer than that of the bulk high- $k$, the capacitance of the stack high- $k$ /interfacial layer is lower than that of a high- $k$ single layer with the same total physical thickness.

Many factors determine the interfacial layer thickness. For example, interfacial layer thickness is found to be dependent on the gate material (Novkovski, 2006; Park et al., 2014). Detailed list of the factors determining the interfacial layer thickness and composition has to be a part of the future investigations. Several processes are proposed for thickness control. Interfacial thickness can be reduced to some tenths of a nanometer or even eliminated by certain technological processes; however, excessive application of these processes leads to a formation of silicides (Xiuyan et al., 2014). A kind of natural thickness saturation is perceptible in some cases. For example, in the case of $\mathrm{Ta}_{2} \mathrm{O}_{5}$ on $\mathrm{Si}$, after oxygen anneals values of about $3 \mathrm{~nm}$ are obtained (Lau, 2012). These values are close to the values for the case of $\mathrm{Ta}_{2} \mathrm{O}_{5}$ films grown by thermal oxidation of Ta (Karmakov et al., 2012).

Although the interfacial layer degrades significantly the MOS structure capacitance, it has rather important beneficial effects. The presence of such an ultrathin layer substantially modifies the band offsets. It has been shown that in metal- $\mathrm{Ta}_{2} \mathrm{O}_{5} / \mathrm{SiO}_{2}-\mathrm{Si}$ structures leakage current is limited by injection of electrons from the substrate at positive gate (band offset $3.15 \mathrm{eV}$ ) and with the injection of the holes from the substrate at negative gate polarity (band offset $4.7 \mathrm{eV}$ ) (Novkovski and Atanassova, 2004). Thus, the band offsets of the stacked layer attain significantly higher values than these for high- $k$ itself, leading to substantial reduction of the leakage current. As a result, combining interfacial layer and high- $k$ dielectric, low leakage simultaneously with high capacitance can be obtained, leading to rather low-equivalent oxide thickness at acceptable level of leakage current for further generations of integrated circuits. Besides, the presence of an interfacial $\mathrm{SiO}_{2}$ layer allows maintaining the density of interface states at acceptably low level (Yang et al., 2012; Litta et al., 2014).
Possibilities of decrease of the equivalent oxide thickness by reducing the interfacial layer are limited, since subsequent processes at higher temperature cause additional growth of the layer. Better solution for decreasing the equivalent oxide thickness is the nitridation of the interfacial layer; nitridation increases the dielectric premittivity of this layer and hence decreases the equivalent oxide thickness of the entire stack. Various nitridation processes are introduced to improve the stacked dielectric layer properties (Houng et al., 2001). The main advantage of these processes is the increase of the interfacial layer permittivity (oxynitride) leading to decreased equivalent oxide thickness (Novkovski and Atanassova, 2005). However, a decrease of band offsets diminishes the positive effect of the nitridation. Therefore, optimum conditions for fabrication of dielectric stacks are to be identified in order to benefit at maximum from the nitridation process (Novkovski, 2009). Additionally, nitridation improves the dielectric integrity of the stack and hence the reliability of the devices based on it. There are many technological parameters to play with in the search for optimum conditions for a particular process. Further improvements with choosing the right combination of properties of the parts of the stack are to be expected.

Another important issue concerns the choice of the gate metal. Even if the metal gate is not in direct contact with the interfacial layer, in the case of nanosized films, it influences strongly its thickness and properties (Novkovski and Atanassova, 2015).

\section{OPEN ISSUES}

Many concepts used in description of silicon dioxide are nowadays used without serious reconsideration for description of high- $k$ dielectrics. In some cases, such an approach is justified. However, in certain cases straightforward application of such concepts, measurement methods, and analysis is shown to be misleading, as is the case with the determination of conduction mechanisms (Novkovski, 2007). Therefore, in the future, much more attention is to be paid to the reconsideration of the applicability of the concepts and methods used in the description and prediction of the properties of the MOS structures containing high-permittivity dielectric layer.

Among the methods to be discussed is the determination of the density of the charges in the dielectric. In the considered structures, there are two dielectric materials and three interfaces that can contribute to charge trapping: high- $k$ bulk layer, interfacial layer (silicon dioxide, oxynitride, or silicate), metal/high- $k$ interface, high- $k$ /interfacial layer interface, and the interfacial layer/substrate interface. Various processes of charging and discharging these traps can occur. Standard methods of determination of oxide and interface charges are probably incorrect in many cases; various methods give different results (Miyata, 2012). Very high values of the interface state densities (of the order of $10^{13} \mathrm{eV}^{-1} \mathrm{~cm}^{-2}$ ) at midgap were determined in some cases (Miyata et al., 2014).

In addition, for film thicknesses of the order of $1 \mathrm{~nm}$, some variations in the nature of the conduction mechanism can occur; in tunneling (Fowler-Nordheim, direct and trap assisted) and hopping, as well as in Poole-Frenkel field enhanced emission. Ballistic transport will be important in majority of the cases, since distance to be traveled by electrons emitted from the traps or injected from an electrode is of the order of few atomic radii. Some substantially 
new integral quantum mechanical solution for the dielectric stack or the MOS structure is expected to appear. Such a model will not only give further better insight into physical phenomena in high- $k$ based MOS structures but is also likely to provide solution without using several suppositions and compromises used in currently accepted methods of description of properties of MOS structures.

Based on above indicated progress lines, new technological solutions have to be developed to provide combinations of high- $k$ with appropriate interfacial layers having optimal properties for MOS based microelectronic devices.

\section{REFERENCES}

Alers, G. B., Werder, D. J., Chabal, Y., Lu, H. C., Gusev, E. P., Garfunkel, E., et al. (1998). Intermixing at the tantalum oxide/silicon interface in gate dielectric structures. Appl. Phys. Lett. 73, 1517-1519. doi:10.1063/1.122191

Boyd, I. W., and Wilson, J. I. B. (1987). Silicon-silicon dioxide interface: an infrared study. J. Appl. Phys. 62, 3195-3200. doi:10.1063/1.339320

Dutoit, M., Bouvet, D., Mi, J., Novkovski, N., and Letourneau, P. (1994). Thin $\mathrm{SiO}_{2}$ films nitrided by rapid thermal processing in $\mathrm{NH}_{3}$ or $\mathrm{N}_{2} \mathrm{O}$ for applications in EEPROMs. Microelectron. J. 25, 539-551. doi:10.1016/0026-2692(94)90039-6

Engstrom, O., Mitrovic, I. Z., and Hall, S. (2012). Influence of interlayer properties on the characteristics of high- $k$ gate stacks. Solid-St. Electron. 75, 63-68. doi:10.1016/j.sse.2012.04.042

Houng, M. P., Wang, Y. H., Horng, J. H., and Huang, R. C. (2001). Effect of annealing on tantalum pentoxide films in $\mathrm{N}_{2}$ and $\mathrm{N}_{2} \mathrm{O}$ gas environments. Jpn. J. Appl. Phys. 40, 5079-5084. doi:10.1143/JJAP.40.5079

Houssa, M., Pantisano, L., Ragnarsson, L.- $\AA$, Degraeve, R., Schram, T., Pourtois, G., et al. (2006). Electrical properties of high- $k$ gate dielectrics: challenges, current issues, and possible solutions. Mat. Sci. Eng. R 51, 37-85. doi:10.1016/j.mser.2006.04.001

Jaccodine, R. J., and Schlegel, W. A. (1966). Measurement of strains at $\mathrm{Si}_{-} \mathrm{SiO}_{2}$ interface. J. Appl. Phys. 37, 2429-2434. doi:10.1063/1.1708831

Karmakov, Y., Paskaleva, A., and Atanassova, E. (2012). Interfacial layers in $\mathrm{Ta}_{2} \mathrm{O}_{5}$ based stacks and constituent depth profiles by spectroscopic ellipsometry. Appl. Surf. Sci. 258, 4507-4512. doi:10.1016/j.apsusc.2012.01.017

Kittl, J. A., Opsomer, K., Popovici, M., Menou, N., Kaczer, B., Wang, X. P., et al. (2009). High- $k$ dielectrics for future generation memory devices (invited paper). Microelectron. Eng. 86, 1789-1795. doi:10.1016/j.mee.2009.03.045

Lau, W. S. (2012). Mechanism of difficulty to study the physics of leakage current reduction by nitridation of silicon before high- $k$ dielectric deposition due to change in nucleation characteristics and some other factors. ECS Trans. 45, 159-166. doi:10.1149/1.3700882

Litta, E. D., Hellström, P.-E., Henkel, C., and Östling, M. (2014). Electrical characterization of thulium silicate interfacial layers for integration in high-k/metal gate CMOS technology. Solid-St. Electron. 98, 20-25. doi:10.1016/j.sse.2014.04.004

Mi, J., Bouvet, D., Letourneau, P., Xanthopoulos, N., Mathieu, H. J., Dutoit, M., et al. (1993). High-resolution SIMS profiling of nitrogen in ultra-thin $\mathrm{SiO}_{2}$ films nitrided by RTP in $\mathrm{NH}_{3}$ and $\mathrm{N}_{2}$ O. Microelectron. Eng. 22, 81-84l.

Miyata, N. (2012). Study of direct-contact $\mathrm{HfO}_{2} / \mathrm{Si}$ interfaces. Materials 5, 512-527. doi:10.3390/ma5030512

Miyata, N., Ohtake, A., Ichikawa, M., Mori, T., and Yasuda, T. (2014). Electrical characteristics and thermal stability of $\mathrm{HfO}_{2}$ metal-oxide-semiconductor capacitors fabricated on clean reconstructed GaSb surfaces. Appl. Phys. Lett. 104, 232104. doi:10.1063/1.4882643

Nakazawa, M., Kawase, S., and Sekiyama, H. (1989). Investigation of the $\mathrm{SiO}_{2} / \mathrm{Si}$ interface. I. Oxydation of a clean $\mathrm{Si}(100)$ surface using photoemission spectroscopy with synchrotron radiation. J. Appl. Phys. 65, 4014-4018. doi:10.1063/ 1.343323
Novkovski, N. (1999). On the impeded growth of oxide films on $\mathrm{Si}$ in $\mathrm{N}_{2} \mathrm{O}$ ambient. Appl. Phys. A 68, 573-575. doi:10.1007/s003390050943

Novkovski, N. (2006). Conduction and charge analysis of metal (Al, W and $\mathrm{Au}$ )$\mathrm{Ta}_{2} \mathrm{O}_{5} / \mathrm{SiO}_{2}-\mathrm{Si}$ structures. Semicond. Sci. Technol. 21, 945-951. doi:10.1088/ 0268-1242/21/7/020

Novkovski, N. (2007). Limitations in the methods of determination of conduction mechanisms in high-permittivity dielectric nano-layers. Physica B 398, 28-32. doi:10.1016/j.physb.2007.04.012

Novkovski, N. (2009). Analysis of the improvement of $\mathrm{Al}-\mathrm{Ta}_{2} \mathrm{O}_{5} / \mathrm{SiO}_{2}-\mathrm{Si}$ structures reliability by Si substrate plasma nitridation in $\mathrm{N}_{2} \mathrm{O}$. Thin Solid Films 517, 4394-4401. doi:10.1016/j.tsf.2009.01.141

Novkovski, N., and Atanassova, E. (2004). Injection of holes from the silicon substrate in $\mathrm{Ta}_{2} \mathrm{O}_{5}$ films grown on silicon. Appl. Phys. Lett. 85, 3142-3144. doi:10.1063/1.1804235

Novkovski, N., and Atanassova, E. (2005). Dielectric properties of $\mathrm{Ta}_{2} \mathrm{O}_{5}$ films grown on silicon substrates plasma nitrided in $\mathrm{N}_{2}$ O. Appl. Phys. A 81, 1191-1195. doi:10.1007/s00339-004-3019-x

Novkovski, N., and Atanassova, E. (2006). Approaching the limit of the $\mathrm{SiO}_{2}$ possibilities for application in nanoscale microelectronics. J. Optoelectron. Adv. Mat. 3, 1238-1242. Available from: http://joam.inoe.ro/arhiva/pdf8_3/3Novkovski.pdf

Novkovski, N., and Atanassova, E. (2015). Leakage current characteristics of metal (Ag,TiN,W)-Hf: $\mathrm{Ta}_{2} \mathrm{O}_{5} / \mathrm{SiO}_{x} \mathrm{~N}_{y}$-Si structures. Mat. Sci. Semicond. Proc. 29, 345-350. doi:10.1016/j.mssp.2014.06.007

Park, I.-S., Jung, Y. C., Lee, M., Seong, S., and Ahn, J. (2014). Electrode dependent interfacial layer variation in metal-oxide-semiconductor capacitor. J. Phys. Conf. Ser. 54, 012004. doi:10.1088/1757-899X/54/1/012004

Wakui, S., Nakamura, J., and Natori, A. (2007). Dielectric properties of the interface between $\mathrm{Si}$ and $\mathrm{SiO}_{2}$. Jpn. J. Appl. Phys. 46, 3261-3264. doi:10.1143/JJAP.46.3261

Wilk, G. D., Wallace, R. M., and Anthony, J. M. (2001). High-k gate dielectrics: current status and materials properties considerations. J. Appl. Phys. 89, 5243-5275. doi:10.1063/1.1361065

Wong, H., and Iwai, H. (2006). On the scaling issues and high- $k$ replacement of ultrathin gate dielectrics for nanoscale MOS transistors. Microelectron. Eng. 83, 1867-1904. doi:10.1016/j.mee.2006.01.271

Xiuyan, L., Takeaki, Y., Tomonori, N., Kosuke, N., and Akira, T. (2014). $\mathrm{HfO}_{2}-$ assisted $\mathrm{SiO}_{2}$ reduction in $\mathrm{HfO}_{2} / \mathrm{SiO}_{2} / \mathrm{Si}$ stacks. Thin Solid Films 557, 272-275. doi:10.1016/j.tsf.2013.10.142

Xue, K., Ho, H. P., and Xu, J. B. (2007). Local study of thickness-dependent electronic properties of ultrathin silicon oxide near $\mathrm{SiO}_{2} / \mathrm{Si}$ interface. J. Phys. D Appl. Phys. 40, 2886-2893. doi:10.1088/0022-3727/40/9/033

Yang, W., Sun, Q.-Q., Fang, R. C., Chen, L., Zhou, P., Ding, S.-J., et al. (2012). The thermal stability of atomic layer deposited $\mathrm{HfLaO}_{\mathrm{x}}$ : material and electrical characterization. Curr. Appl. Phys. 12, 1445-1447. doi:10.1016/j.cap.2012.03.035

Conflict of Interest Statement: The author declares that the research was conducted in the absence of any commercial or financial relationships that could be construed as a potential conflict of interest.

Received: 06 October 2014; accepted: 24 November 2014; published online: 08 December 2014.

Citation: Novkovski N (2014) Peculiarities of the interface between high-permittivity dielectrics and semiconductors. Front. Mater. 1:30. doi: 10.3389/fmats.2014.00030

This article was submitted to Colloidal Materials and Interfaces, a section of the journal Frontiers in Materials.

Copyright (C) 2014 Novkovski. This is an open-access article distributed under the terms of the Creative Commons Attribution License (CC BY). The use, distribution or reproduction in other forums is permitted, provided the original author(s) or licensor are credited and that the original publication in this journal is cited, in accordance with accepted academic practice. No use, distribution or reproduction is permitted which does not comply with these terms. 